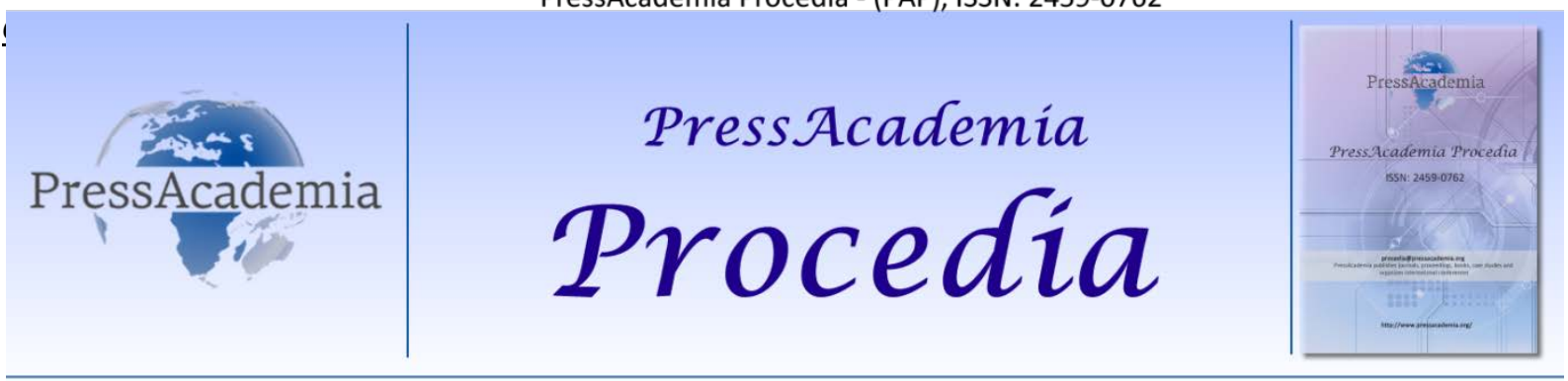

Global Business Research Congress (GBRC), May 26-27, 2016, Istanbul, Turkey.

\title{
THE IMPORTANCE OF PERSONALITY STRUCTURE WITHIN AN ORGANIZATION
}

\section{DOI: 10.17261/Pressacademia.2016118661}

\author{
Gulay Tasdemir ${ }^{1}$, Gulseren Keskin ${ }^{2}$, Elif Aktekin ${ }^{3}$ \\ ${ }^{1}$ Pamukkale University, gyigitoglu@pau.edu.tr \\ ${ }^{2}$ Ege University, unalgulseren@hotmail.com \\ ${ }^{3}$ Ege University. elif aktekin@hotmail.com
}

\begin{abstract}
Purpose: In this article, it is aimed to debate the importance of personality structure within organization and to evaluate its results. Method: For this article, in international and national databases were reviewed. Findings: The harmony between the work to be done and the individual's personality is an important subject which needs a focus in terms of people and organizations. In the situation of unability to select appropriate individual to the work, the additional costs stem from the re-recruitment process, the time spent for adjustment process of new employee and the negative results of occupational-work accidents cause extra costs for organization. Furthermore there are different personality types. A type personalities are aggressive, impatient and business-oriented even B type personalities are experiences less conflict with other individuals and time and also they are more stable. Discussion: It is supported with scientific researches that there is a significant relationship between personality characteristics of employees and organizational variables such as job satisfaction, leadership, conflict management styles. Result: In order to create a positive atmosphere within the organization to employees, the regular training programs such as communication, dealing with stress, self-knowledge, and personality features are very important for the welfare of the organization.
\end{abstract}

Keywords : Factors affecting personality, organization, organizational variables, personality, personality types.

JEL Codes : $110,119,120$

\section{ÖRGÜT ORTAMINDAKI KIŞiLIK YAPILARININ ÖNEMI}

\section{ÖZET}

Amaç: Bu yazıda örgüt ortamındaki kişilik yapılarııı önemi konusunu tartışmak ve sonuçlarını değerlendirmek amaçlanmaktadır. Yöntem: Bunun için, Uluslararası ve Ulusal veri tabanlarındaki makaleler taranmıştır. Bulgular: Yapılacak olan iş ile bireyin kişiliğinin uyumu kişiler ve örgütler açısından üzerinde durulması gereken önemli bir konudur. İşe uygun kişinin seçilememesi durumunda; işe alım sürecinin tekrar izlenmesinin doğurduğu ek giderler, iş görenin işe alışması sürecinde geçen zaman ve olası iş kazalarının doğurduğu olumsuz sonuçlar örgüte ekstra masraflar doğurmaktadır. Ayrıca farklı kişilik tipleri vardır. A tipi kişilikler; agresif, sabırsız ve iş merkezlidir. B tipi kişilikler ise; kişilerle, zamanla daha az çatışma halindedir ve yaşama karşı daha dengelidir. Tartışma: Çalışanların kişilik özellikleri ile iş tatmini, liderlik, çatışma yönetim tarzları gibi örgütsel değişkenler arasında anlamlı bir ilişki olduğu bilimsel çalışmalarla desteklenmektedir. Çalışanlara düzenli olarak iletişim, stresle baş etme, kendini tanıma, kişilik özellikleri gibi eğitim programlarına yer verilmesi örgütlerin refahı açısından önemlidir.

Anahtar Kelimeler: Kişilik, kişilik tipleri, kişiliği etkileyen faktörler, örgüt ortamı, örgütsel değişkenler.

JEL Kodları: I10, I19, I20 


\section{GiRiş}

İ̧̧ yaşamında en önemli üretim faktörü insan gücüdür. İyi ürün ve hizmet üretiminin gerçekleştirilmesi için üretilecek ürün ve hizmet için gerekli donanıma sahip ve işini isteyerek yapan insan gücüne gereksinim duyulmaktadır. Doğru işe doğru eleman seçememenin örgütlere maliyeti ağır olmaktadır (Tanrıverdi, 2012). Kişilik konusu örgütsel davranış ve insan kaynakları yönetimi açısından birçok boyutta ele alınan önemli bir konudur. Örgütsel davranış disiplini kapsamında çalışan davranışlarını daha iyi anlama, çalışan davranışlarının çalışma hayatı ile birlikte değişimini analiz etme ve yorumlama, örgüt ve çalışan davranışı arasındaki etkileşimi inceleme imkânını sunması açısından kişilik konusu, örgüt yöneticileri tarafından üzerinde durulması gereken bir alandır (Aytaç, 2001). İnsan kaynakları yönetimi açısından bakıldığında ise iş gören adaylarının işin niteliklerine uygunluğunun sınanması, işin iş gören adaylarının beceri ve beklentilerini karşılama potansiyelinin tespit edilebilmesi açısından kişilik konusu önemli rol oynamaktadır. Ayrıca çalışanların kişilik özellikleri ile iş tatmini, liderlik, çatışma yönetim tarzları gibi örgütsel değişkenler arasında anlamlı bir ilişki olduğu yapılan bilimsel çalışmalar tarafından desteklenmektedir (Rothmann ve Coetzer, 2003; Ellingson ve ark., 2007; Morgeson ve ark., 2007; Parikh ve Gupta, 2010; Lee ve Wu, 2011; Robbins ve Judge, 2013).

Örgütlerde birbirlerinden farklı pozisyonların olması, pozisyonlara uygun nitelikte, yetenekte ve kişilik özelliklerine sahip iş görenlerin istihdam edilmesini zorunlu hale getirmiştir. İ̧̧ görenlerin örgüte uyum sağlayabilmeleri için, kişilik yapılarının yapacakları işe, iş arkadaşlarına ve örgüte uygunluğu gerekmektedir. Çünkü kişilik yapıları, bireylerin meslek seçimlerini, iletişim kurma şekillerini, olayları algılamalarını ve verdikleri tepkileri etkilemektedir. Bu yazıda örgüt ortamındaki kişilik yapılarının önemi konusunu tartışmak ve sonuçlarını değerlendirmek amaçlanmaktadır.

\section{LITERATÜR TARAMASI}

\section{1. Kişilik Tanımı ve Özellikleri}

Farklı kişilik tanımları bulunmakla birlikte literatür incelendiğinde yaygın kullanılan kişilik tanımlarından bahsetmek mümkündür. Psikologlar kişiliği bireyin tüm psikolojik sisteminin büyüme ve gelişmesini ifade eden bir kavram olarak değerlendirmektedirler (Robbins, 2012). Akademisyenler ise farklı kuramsal temeller aracılığıyla kişiliği ele almaktadır (Luthans, 2010). Kişilik kavramı; bireyin iç ve dış çevresiyle kurmuş olduğu ve diğer insanlardan ayırt edici ve tutarlı olan, yapılaşmış bir ilişki şeklidir (Cüceloğlu, 2011). Kişilik, bireyi kendisine özgü yapan; dış görünüş, zihinsel özellikler, takıntılar, alışkanlıklar, tavırlar, tutumlar ve özellikle davranışlarına kadar pek çok özelliği kapsayan bir bütün olarak tanımlanmaktadır (Fındıkçı, 2009). Bu kapsamda kişilik; "bireyi diğerlerinden ayıran nispeten kalıı özellikler ve eğilimlerdir" veya "bireyler tarafından sergilenen özgün ve nispeten sabit davranış, düşünce ve duygu kalıbıdır" şeklinde tanımlanabilir. Bu bakımdan kişilik özellikleri bir bakıma bireyi özgün kılan ve bireyin yoğunlukla sergilediği davranışlarına verilen isim olarak ifade edilebilir. Ancak belirtmek gerekir ki bireyin öncelikleri, tercihleri, dünya ile başa çıkma tarzı ve çevre tarafından nasıl algılanmak istediği gibi unsurlar da kişiliğin şekillenmesinde rol oynayabilmektedir.

Fiziksel, zihinsel ve duygusal yönden pek çok farklılık gösteren bireyler, bunun sonucunda olayları ve olguları da farklı şekilde yorumlarlar. Bu farklılıklar kişiliğin temelini oluşturur (Durna, 2005). Diğer yandan bireylerin yaşadığı çevrelerin de farkıı olması bireyleri değişik uyarıcıların etkilemesine sebep olur. Çünkü farklı çevresel faktörlerin etkisinde kalan birey söz konusu unsurlardan etkilenebilmekte ve zamanla kişilik özellikleri de farklılaşabilmektedir.

Kişiliğin dinamik bir özelliği vardır. Kişilik özelliklerinin tutarlılık sergilemesi, değişmeyeceği anlamına gelmemektedir. Çünkü kişilik çevresel faktörlerin etkisi ile değişiklik gösterebilir (Başaran, 2000). Öte yandan bireyin zihinsel ve fiziksel gelişim evresinde etkileşim ve iletişimde bulunduğu birey ve gruplar, bireyin kişiliğini etkilemede farklı etkilerde bulunabilir. Bu durum ise kişiliğin zamanla değişebileceğini göstermektedir (Robbins, 2012). Örneğin bireyin katıldığı kültür ve eğitim faaliyetleri zamanla bireyin davranış ve alışkanlıklarını değiştirebilmektedir. Bu durum, zamanla bireyin kişilik özelliklerinin de değişmesine zemin hazırlayabilir. 
Kısacası kişiliğin hem kalıtımsal hem de birçok çevresel faktörün etkisiyle oluşup gelişmesi kişiliğin dinamik özelliğini göstermektedir (Parikh ve Gupta, 2010).

\section{2. Kişiliği Etkileyen Faktörler}

Kişiliğin oluşumunda ve gelişiminde çevresel faktörlerin mi yoksa kalıtımsal özelliklerin mi etkili olduğu hususu tartışmalı bir konudur. Bu konuda araştırmacıların farklı görüşleri olsa da ilgili literatür incelendiğinde kişiliğin şekillenmesinde hem kalıtsal hem de çevresel özelliklerin etkili olduğu görülmektedir (Robbins, 2012). Bu bakımdan kişiliğin gelişimini ve değişimini öğrenme, kalıtım, çevre gibi birçok farklı faktörle ilişkilendirmek gerekmektedir (Luthans, 2010).

Kalıtım: Kişiliği etkileyen faktörlerin en önemlilerinden birisi kalıtımdır. Kalıtım, bireyin anne ve babasının birtakım özelliklerinin kromozomlar vasıtasıyla bireye geçmesini ifade etmektedir. Bireyin fiziksel duruşu, yüz güzelliği, beden ve kas yapısı gibi özellikler, kalıtımsal özellikleridir (Robbins, 2012).

Aile: çocukları üzerinde baskı kurmayan, demokratik bir aile yapısının benimsendiği bir ailede yetişen kişilerin başarı güdülerinin, diğer kişilerle kıyaslandığında daha yüksek olduğu belirtilmektedir. Anne-babanın demokratik bir yapıya sahip olması, çocuğun daha rahat yetişmesine, objektiflik kazanmasına, rasyonel davranmasına ve zamanla daha aktif olup daha kolay sosyal ilişki kurmasına olanak sağlamaktadır. Aile bireyleri, çocuğa çeşitli yollarla deneyimlerini aktardıkları için ailenin yetiştirme biçimi de kişiliği belirleyici bir unsurdur. Ayrıca kişilik gelişiminde aile içerisinde en önemli olan ve etkili olan kişi annedir. Kişilerin anneleriyle geçirdikleri hayatlarının ilk zamanları, ileri dönemlerdeki algılayışlarını ve davranışlarını etkilemektedir. (Özkalp, 2002)

Çevresel Faktörler: Kişiliğin oluşumunda ve gelişiminde kültür, kişinin bir gruba üyeliği ve hayat deneyimi önemli bir unsurdur. Kişiliğin oluşumunda bireyin içinde doğup büyüdüğü coğrafi çevrenin etkisinden bahsetmek mümkündür (Allık ve Mccrae, 2004). Çünkü bireyin yetiştiği bölgenin iklimi, fiziksel özellikleri ve benzer unsurlar bireyin yaşam tarzına ve dolaylı olarak da kişilik özelliklerine etki edebilmektedir (Eroğlu, 2010).

Bedensel Faktörler: Bedensel faktörlerin kişilik yapısına etkisi, araştırmacılar tarafından çoğunlukla hayvan deneyleri ve tek yumurta ikizleri üzerinde yapılan çalışmalarla ortaya konulmaya çalışılmıştır (Çetin \& Beceren, 2007). Yapılan araştırmalar, büyüme ve bedensel gelişme hızının kişiliği belirli gelişim dönemlerinde etkilediğini göstermiştir. Bu özellikler ergenlik döneminde özellikle önem kazanmaktadır. Yapılan araştırmalar sonucunda uzun boylu kişilerin kısa boylulara nazaran daha fazla otoriter oldukları ortaya konulmuştur (Işır, 2006).

Farklı kişilik sınıflamaları bulunmaktadır. Bu sınıflamalar içerisinde S. Freud'un, E. Berne'nin, A. Adler'in, C. Jung'un, K. Horney'in, H. J. Eysenck'in, J. L. Holland’ın kişilik kuramı, W. Norman’ın Beş Faktör Kişilik Modeli ve M. Friedman ve R.H. Roseman'ın A ve B Kişilik Tipleridir. A ve B Kişilik Tipleri stres kavramıyla ilişkilendirilerek ortaya çıkmıştır (Avcı ve Kaya, 2010). Bu anlamda değişim iş görenler üzerinde stresin kaynağının nedeni olabileceği için A ve B Kişilik Tiplerinin örgüt ortamındaki etkilerinden bahsedilecektir.

\section{3. A Tipi ve B Tipi Kişilik Yapısı}

A tipi ve B tipi kişilik ilk olarak iki kardiyolog Meyer Friedman ve Rosenman tarafından gözlemlenmiştir. Fikir ilk defa, oturma odasının sandalyelerini tamir eden döşemecinin sandalyelerin çoğunun sadece önden yırtıldığını söylemesi üzerine ortaya çıktı. Bu durumdan, iki kardiyolog da kalp hastalarının çoğunun endişeli olduklarını ve otururken zor zamanlar geçirdiklerini anladılar. Bu gözlemi başlangıç noktası olarak kullanan ve kendi klinik uygulamalarını da temel alan Friedman ve Rosenman hastalarının iki farklı davranış modeli sergilediği sonucuna vardılar. Araştırmaları onları farklılıkların kişilik temelli olduğu sonucuna götürdü (Moorhead \& Ricky, 1992; Soysal, 2008).

A tipi davranış biçimine sahip birey aşırı rekabetçi, kendisini işine adamış ve zamana oldukça duyarlıdır. Bu birey agresif, sabırsız, işe odaklı ve mümkün olduğu kadar çok kısa sürede başarılı olmak istemektedir. Zaman baskısından hoşlanır ve aceleci tavır takınarak kendini sürekli bir şeyler yapmak zorunda hisseder. Zamanını çok iyi yönettiği söylenemez (Aytaç, 2002). Tatilde bile hareketsizliği sevmez, çabuk olmayan insanlara kızar ve oldukça yoğun çalışır ve mesai arkadaşlarından da aynı şeyi bekler. Kendini çoğu zaman başka insanlara göre 
daha enerjik hisseder. Beklemeye hiç tahammülü yoktur. A tipi bireye karsı açık olunması, hoşgörü gösterilmesi, güveninin kazanılması, anlamsız rekabete girilmemesi bu tip kişilerle ilişkide yararlı olmaktadır (Baltas \& Baltas, 2000)

B tipi davranış biçimine sahip bireyse, tersine daha az rekabetçi, işine kendisini daha az adayan ve zamana karşı daha az duyarlıdır. Bu tür insanlar zamanla daha az çatışma halindedir ve yaşama karsı daha dengeli ve rahat bir yaklaşım içerisindedir. Kararlı bir hızda çalışır ve kendini daha fazla güven içinde hisseder. B tipi kişinin A tipi kişiden daha çok ya da daha az başarılı olduğu söylenemez. B tipi özellikler daha rahat, uysal, az rekabetçi ve daha az saldırgandır. Zamanla daha az yarışılar, boş zaman etkinliklerine daha çok fırsat tanırlar. Bu tür davranışların istenirse değiştirilmesi olanaklıdır. B tipi insanlar katı kurallardan arınmış ve esnektirler. Başarı konusunda aşırı hırslı değildirler. Çok kolay sinirlenmez ve tedirgin olmazlar. Yaptıkları işten zevk almayı bilirler. İşlerinde rahat olmaları onlarda suçluluk duygusu oluşturmaz, sakin ve düzenli çalışırlar. Çevresinden ve kendisinden emin kişilerdir (Güney, 2000).

A ve B tipi davranış özellikleri, kişiliği biçimlendiren yüzlerce özellikten biridir. Bundan dolayı, karmaşık çok boyutlu bir insanı bütünüyle tanımlayan bir özellik değildir. A ve B tipi, yaşam içinde ortaya konan bir tutum ve davranış biçimidir. B tipi davranış biçiminin özelliklerini taşıyan bir insan, bazen A tipi davranış biçimi özelliği de gösterebilir. Dünyada hiç bir insan A tipi davranış biçiminin bütün özelliklerini aynı baskınlıkta sahip olmadığı gibi aynı sıklıkta ortaya koymaz. Özelliğin sınıflayıcı ve ayırt edici olması, baskın veya çekinik oluşuna ve ortaya konma sıklığına bağlıdır (Eniseler, 2007).

\section{VERI VE YÖNTEM}

Uluslararası ve Ulusal veri tabanlarında (Türk Tıp Veri Tabanı, Türk Psikiyatri Dizini, Türk Medline, Yüksek Öğretim Kurulu Tez Merkezi, Google Akademik, Medline, Web of Science taranmıştır. 2000-2016 yılları arasında Türkçe anahtar kelime olarak "kişilik, örgüt ortamı, kişilik tipleri"; İngilizce olarak " organization, personality, personality types anahtar kelimeler kullanılmıştır. Bu alana katkılar sağlamış araştırmalardan yararlanılmıştır.

\section{BULGULAR VE TARTIŞMA}

21. yüzyılda teknolojik ilerlemelerin ivme kazanması ile birlikte birçok yeni iş ve pozisyon ortaya çıkmakta ve bazı işlerin yapılış usulü değişmektedir. Özellikle örgütlerde bilgi sistemlerinin kullanımının yaygınlaşması, işlerin yerine getirilmesinde ihtiyaç duyulan niteliklerin farklılaşmasına zemin hazırlamaktadır. Dışa dönük, hareketli ve konuşmayı seven bir bireyin müşteri ve iş arkadaşları ile çok fazla iletişimde bulunulmayan bir ofis ortamında çalışması onu mutsuz edebilir. Çünkü birey doğası gereği daha sosyal bir ortama ihtiyaç duymaktadır. Fakat birey içine kapanık ve diğer bireylerle (müşteri, mesai arkadaşı gibi) iletişim kurmayı sevmeyen biri ise sürekli aktif olunması gereken bir işte mutsuz ve verimsiz olabilmektedir (Aytaç, 2001). Örneğin, muhasebe departmanında çalışan bir bireyin dışa dönük olması çok önemli olmayabilir (Britain, 2007). Buna karşılık, riske girme eğilimi yüksek olan kişiler bazı mesleklerde son derece başarılı olabilirler. Yöneticilik ve borsa brokerliği gibi meslekler bu kişilere uygun olup ani kararlar verilmesi gereken bazı durumlarda yöneticilere ve işletmeye önemli faydalar sağlanabilir (Aytaç, 2001). Bu bağlamda örgütlerde çalışanların ya da iş gören adaylarının kişilik özelliklerinin değerlendirilmesi, sonuçları itibariyle örgütsel süreçlerin işleyişini daha etkin hale getirebilmektedir. Bu nedenle de kişilik konusu literatürde önemli bir yer tutmaktadır. Kısacası yapılacak olan iş ile bireyin kişiliğinin uyumu bireyler ve örgütler açısından üzerinde durulması gereken bir konudur (Özsoy \& Yıldız, 2013).

Kişilik konusu hakkında bilgi sahibi olunması, örgütte yönetsel pozisyonda yer alan bireylerin işlerini yapmalarına katkı sağlayabilir. Bu bakımdan yönetsel pozisyondaki bireyler çalışanların farklı kişilik özellikleri ve değişik kültürel geçmişlerinin olduğunu dikkate almalıdırlar. davranış kaynaklarının daha iyi anlaşılması yöneticilerin empati kurma ve hataları hoş görme gibi yeteneklerini geliştirebilmektedir. Bazı durumlarda benzer davranış kalıpları sergileyen bireylerin örgüt içinde davranışlarının anlaşılması ve belirli durumlarda verebilecekleri olası tepkilerinin tahmin edilebilmesi açısından kişiliğin örgütlerce değerlendirilmesi gerekmektedir (Parikh ve Gupta, 2010). 
Öte yandan örgüt içinde oluşan sorunlar karşısında kişilik özelliklerinden faydalanmak çalışanlar açısından faydalı olabilmektedir. Örneğin olası bir çatışma durumunda baskın bir kişilik özelliğine sahip bireyle tartışmayı sürdürmek, iki taraf için de yıpratıcı olabilir. Böyle bir durumda kişinin bu özelliği bilindiği için farklı yollarla çatışma yönetimi sağlanabilir. Böylelikle sonuç alınamayacak girişimlerden uzak kalınabilir. Bu bakımdan insan davranışlarını anlamada, bireylerin kişilik özelliklerinin değerlendirilmesi ve iyi analiz edilmesi oldukça faydalı olabilmektedir (Ellingson ve ark., 2007).

Örgütlerde kişilik değerlendirme, sadece işe alım aşaması ve insan davranışlarını daha iyi anlama hususlarında değil; bunlarla birlikte, kariyer yönetimi, liderlik, müşteri ilişkileri yönetimi ve takım çalışması gibi birçok örgütsel aktivite bakımından da önemli bir konudur (Ellingson ve ark., 2007; Parikh \& Gupta, 2010). Benzer şekilde kişiliğin, örgütsel başarıda kritik role sahip olan iş performansı (Morgeson ve ark., 2007), yaratıclık (Rothmann \& Coetzer, 2003), eğitimin başarısı, kariyer gelişimi ve liderlik etkinliği gibi önemli örgütsel çıktılarla bağlantılı olduğuna dair bulgulara ulaşılmıştır (Lee \& Wu, 2011). Örgüt içinde meydana gelen gerginlik çatışmaların azaltılmasında, çalışanların kişilik özelliklerinin örgüt içindeki bireyler ile uyuşup uyuşmaması önemli bir husustur. Çünkü bireyin kişiliği iş çevresinden etkilendiği gibi aynı zamanda iş çevresini de etkileyebilir. Örneğin uyumsuz kişiliğe sahip bir birey, örgüt ortamını olumsuz etkileyebilir.

Örgütlerin başarısı için büyük önem taşıyan iş görenlerin kişiliklerini saptamak ve örgütsel bağlııık düzeylerini araştırmak amacıyla, is ortamında bazı iş kriterleri geliştirilir. İş kriterleri, örgütsel davranışlarla ilgili teorilerin sınanması, çeşitli insan kaynakları uygulamalarının geliştirilmesi ve çalışanların bireysel gelişimlerinin sağlanması gibi birçok kuramsal ve uygulamalı konuda araştırmacı ve yöneticilerin ilgilendiği öncelikli konulardan birisi olmuştur (Yelboğa, 2006). İ̧̧ görenlerin kişilikleri bulundukları ortamı bazen olumlu yönde, bazen de olumsuz yönde etkilediği gibi, bulundukları örgütü de etkilemektedir. Örneğin daha çabuk sinirlenen bir kişilik yapısına sahip iş görenlerin örgüt içerisindeki davranışları ile daha geç sinirlenen iş görenlerin örgüt içerisindeki davranışları arasında farklılıklar olabileceğini söylemek mümkündür.

A tipi kişiliğe sahip iş görenler, risk almayı seven, aceleci ve aynı anda birkaç isi birden yapmak isteyen, sabırsız, mesai saatlerinin dışındayken iş düşünen ve evlerine iş götüren, az dinlenen, aceleci, yönlendirilmesi zor olan, sürekli bitmeyen bir yarışma hırsı olan ve üstleri tarafından yanlış anlaşılmaktan sürekli yakınan kişilerdir. A tipi kişiliğe sahip olan iş görenlerin, hırslı olduklarından ve işlerini önemsediklerinden dolayı kişisel anlamda başarıı olduğu kadar, örgüt içerisinde de önemli başarıları olabilen, ön planda olan ve işleri zamanında yetiştirebilen kişiler olduğunu söylemek mümkündür. Bu kişilerin başarı güdüleri çok kuvvetli olduğundan, iş arkadaşlarına düşkünlüklerinin ve bağlııklarının diğer kişilere göre daha düşük, fakat yaptıkları mesleğe bağılıılarının daha yüksek olduğunu söylemek mümkündür (Işır, 2006).

A tipi kişiliğe sahip iş görenlerin örgütleri olumsuz yönde etkileyebilecek olan özelliklerine bakıldığında; acelecilik, beklemeyi sevmeme, düşüncesizce hareket edebilme, planlı yaşamayı sevmeme, zor yönlendirilme ve aşırı hırslı olma gibi özellikler gelmektedir. Bu tipin özelliklerini taşıyan iş görenler, plansız yasamaktan ve aciliyet duygularından dolayı iş yaşamlarında sorun yasayabilmektedirler (L' Abete, 2005). Bu tipin özelliklerini taşıyan iş görenler stres altında çalışırken düşüncesizce konuşabilmekte ve davranabilmektedirler. Ayrıca bu iş görenlerin yönlendirilmeleri diğer iş görenlere oranla daha zor olduğundan dolayı, örgüt içerisinde üstleriyle ve is arkadaşlarıyla iletişimlerinde problem yasayabilmektedirler. Bu durumun sonucunda da bulundukları örgüte olan bağlılıklarında düşüş meydana gelebilmektedir.

B tipi kişilik özelliği taşıyan kişiler, zamanı dikkate almazlar, sabırlıdırlar, kendilerini övmezler, kendilerini sıkmazlar, rahattırlar, sınırlı zamanlı işleri yapmayı ve acele etmeyi sevmezler, yumuşak huyludurlar, yetkilerini devrederler (Tokat, Kara, \& Kara, 2013).

B tip kişiliğe sahip iş görenlerin örgütleri olumsuz yönde etkileyebilecek olan özellikleri incelendiğinde ise hırslı olmama, profesyonellikten uzak düşünme, risk almaktan kaçınma, başarıya yönelik güdülenmesi düşük olma ve özel hayata gereğinden fazla yönelme özellikleridir. B tipi kişilik özelliklerine sahip iş görenler, profesyonel düşünme konusunda zorluk çektiklerinden, iş yaşamına gereken önemi göstermediklerinden, risk almaktan sürekli kaçındıklarından ve rekabet isteklerinin olmamasından dolayı örgüt içerisinde sorunlar yasayabilmektedirler. İ̧ yaşamına gereken önemi göstermeyen B tipi iş görenler, kendilerinden beklenenleri 
sağlama ve özel hayat ile iş hayatı arasındaki dengeyi koruyabilme konularında zorluk yasamaktadırlar. Bunun sonucunda ise iş tatminleri ve örgüte olan bağılıkları azalmaktadır (L' Abete, 2005; Tokat, Kara, \& Kara, 2013).

\section{SONUÇ}

Kişilik kavramı örgüt ortamında önemli bir yere sahiptir. İş görenlerin sahip olduğu bir kişilik özellikleri onu başarıya götürürken taşıdığı başka bir özelliği başka bir konuda başarısızlığa itebilir. Yöneticilerin iş görenleri tanıyıp anlamaları, iş görenlerin de çalışma arkadaşlarıyla iyi bir iletişim ve uyum içinde çalışabilmeleri kişilik konusunu iyi kavrayabilmelerine bağlı olacaktır. Bir iş gören, kişiliğinin olumlu ve olumsuz özelliklerinin farkında olup, olumlu olan özelliklerini öne çıkartmalı ve başarısını engelleyebilecek özelliklerini de en az düzeyde sergilemeye özen göstermelidir. Günümüze kadar gelmiş ve kişilik kavramını tanımamıza yardımcı olan pek çok kişilik tipi bulunmaktadır. Bu kişilik tipleri sosyal yaşamda kişileri tanımamıza kolaylık sağladığı kadar örgüt yöneticilerine de iş görenlerini tanıma da yol gösterici olabilmektedir. İş görenlerin sahip oldukları kişilik tipleri değişime uygun davranışlar sergilemelerinde etkili olacaktır.

Daha yüksek verim elde etmeyi ve daha kaliteli işler çıkmasını isteyen örgütlerin iş görenlerini işin gereklerine göre seçmeleri gerekmektedir. Rutin ve program temelli işlerde daha kuralcı kişilikte olan, koşulları belirli olan çalışma ortamında iyi performans gösteren kişilik özelliklerini taşıyan iş görenleri seçmek önemli olmaktadır. Sürekli değişen ve gelişen işlerde ise esnek olabilmeyi gerektiren çalışma ortamında iyi performans gösteren kişilik özelliklerini taşıyan kişileri seçmek örgütte insan kaynağını iyi kullanabilmek açısından önemli olabilecektir.

İşe alım ve terfi kararlarında pozisyonun gerektirdiği niteliklerden yola çıkılarak oluşturulan kriterlere uygun kişilik özelliklerinin tespit edilmesi, orta ve üst kademe yöneticilerinin insan ilişkilerinde daha etkin olabilmeleri ve görevlerini daha etkili bir şekilde yerine getirebilmeleri için kişilik konusu hakkında eğitim programlarının düzenlenmesi, çalışanların örgüt içi çatışmalarda daha etkin olabilmeleri ve örgüt içi pozitif bir atmosfer oluşturabilmek için periyodik iletişimle ilgili eğitim programlarına yer verilmesi (kişilik, empati, ben dili ile iletişim, kendini tanıma, öfke, çatışma ve stres yönetimi, insan davranış özellikleri) gibi konuların örgütlerin uygulamalarına dahil edilmesinin oldukça önemli olacağı düşünülmektedir.

\section{KAYNAKLAR}

Allık, J., \& Mccrae, R. 2004, "Toward a Geography of Personality Traits", Journal of Cross-Cultural Psychology, vol. 35, no. 1, pp. 13-28.

Avcı, U., \& Kaya, U. 2010, "Yıldırma (Mobbing) ve Kişilik İlişkisi: Hizmet Sektörü Çalışanları Üzerinde Bir Araştırma”, Afyon Kocatepe Üniversitesi IiBF Dergisi, Cilt 12, Sayı 12, ss.51-79.

Aytaç, S. 2001, "Örgütsel Davranış Açısından Kişiliğin Önemi”, İş, Güç Endüstri Ilişskileri ve İnsan Kaynakları Dergisi, cilt 3, sayı 1, sıra: 1 / No: 96.

Aytaç, T. 2002, "Eğitim ve Yönetimde Yeni Yaklaşımlar Zaman Yönetimi", Bilim ve Aklın Aydınlığında Eğitim Dergisi, Temmuz, http://yayim.meb.gov.tr/yayimlar/sayi29/aytac.htm.

Baltaş, A., \& Baltas, Z. 2000, Stres ve Başaçıkma Yolları. İstanbul: Remzi Kitapevi.

Başaran, İ. E. 2000, Örgütlerde Davranış. Insanın Üretim Gücü. Ankara: Feryal Matbaası.

Britain, R. 2007, Incorporating Personality Traits in Hiring: A Case Study of Central Texas Citie. Applied Research Projects, Texas State University-San Marcos.https://digital.library.txstate.edu/bitstream/handle/10877/3776/fulltext.pdf.

Cüceloğlu, D. 2011, Insan ve Davranış Psikolojinin Temel Kavramları. İstanbul: Remzi Kitapevi.

Çetin, N. G., \& Beceren, E. 2007, “Lider Kișilik: Gandhi”, Süleyman Demirel Üniversitesi Sosyal Bilimler Enstitüsü Dergisi, cilt 3, sayı 5, ss. 110132.

Durna, U. 2005, "A ve B Tipi Kişilik Yapılarını ve Bu Kişilik Yapılarını Etkileyen Faktörlerle İlgili Bir Araştırma”, iktisadi ve Idari Bilimler Dergisi, cilt 19 , sayı 1 , ss. $276-290$. 
Ellingson, J. E., Sackett P. R., \& Connelly, B. S. 2007, "Personality Assessment Across Selection and Development Contexts: Insights into Response Distortion", Journal of Applied Psychology, vol. 92, pp. 386-395.

Eniseler, A. G. 2007, "Kalp-Damar Hastalarında A Tipi Davranış ve Öfke Analizi”, Celal Bayar Üniversitesi Fen Bilimleri Enstitüsü Yüksek Lisans Tezi, Manisa.

Eroğlu, F. 2010, Davranış Bilimleri. İstanbul: Beta Basım ve Yayım Dağııım Anonim Şirketi.

Fındıkçı, i. 2009, Insan Kaynakları Yönetimi. İstanbul: Alfa Yayınları.

Güney, S. 2000, Davranış Bilimleri. Ankara: Nobel Yayınları.

Işır, T. 2006, "Örgütlerde Personel Seçim Süreci: Bir Kamu Kurulusundaki Yönetici Personelin Kişilik Özelliklerinin Tespit Edilerek Personel Seçim Sürecinin İyileştirilmesi Üzerine Bir Araştırma”, Çukurova Üniversitesi Sosyal Bilimler Enstitüsü Doktora Tezi, Adana.

L' abete, L. 2005, Personality And Intimate Relationships: Socialization And Psychopathology. New York: Springer Press.

Lee, F. H., \&. Wu, W. Y. 2011, "The Relationships Between Person-Organization Fit, Psychological Climate Adjustment, Personality Traits, and Innovative Climate: Evidence From Taiwanese Hightech Expatriate Managers in Asian Countries", African Journal of Business Management. vol. 5, no. 15, pp. 6415-6428.

Luthans, F. 2010, Organizational Behaviour. An Evidence Based Approach. Mcgrow Hill. N.Y.

Morgeson, F. P., Reider, M. H., \& Campion, M. A. 2005, "Selecting Individuals in Team Settings: The Importance of Social Skills, Personality Characterıstıcs, and Teamwork Knowledge", Personnel Psychology, vol. 58, no. 3, pp. 583-611.

Moorhead, G. G., \& Ricky, W. 1992, Organizational Behavior. Boston: Houghton Mifflin Company.

Özkalp, E. 2002, Davranış Bilimlerine Giriş. Eskişehir: Anadolu Üniversitesi Açıköğretim Fakültesi.

Özsoy, E., \& Yıldız, G. 2013, “Kişilik Kavramının Örgütler Açııından Önemi: Bir Literatür Taraması”, İșletme Bilimi Dergisi, cilt 1, sayı 2, ss. 1 12.

Parikh, M., \& Gupta, R.2010, Organizational Behavior. Tata McGraw-Hill.

Robbins, S. P., \& Judge, T. A. 2013, Organizational Behavior. Global Edition. England: Pearson Education Limited.

Rothmann, S., \& Coetzer, E.P. 2003, “The big five personality dimensions and job performance", SA Journal of Industrial

Psychology, Vol. 29, no.1, pp. 68-74.

Soysal, A. 2008, "Çalışma Yaşamında Kişilik Tipleri: Bir Literatür Taraması", Ankara: Çimento I̧şverenler Dergisi, cilt 1, sayı 22, ss. 1-19.

Tanrıverdi, H. 2012, "Kişilik Özelliklerinin iş Değerlerine Ve Örgütsel Bağlılık Üzerine Etkisi: Hastane Çalışanları Üzerinde Bir Araştırma", Türkiye Sosyal Araştırmaları Dergisi, vol. 16, no. 2, pp. 189-210.

Tokat, B., Kara, H., \& Kara, M. Y. 2013, “A-B Tipi Kişilik Özelliklerine Sahip İş Görenlerin Olası Bir Örgütsel Değişime Yatkınlıklarının Araştırılması", International Periodical for The Languages, Literature and History of Turkish or Turkic, vol. 8, no. 8, pp. 1973-1988.

Yelboğa, A. 2006, "Kişilik Özellikleri ve İ̧̧ Performansı Arasındaki Iliş̧inin İncelenmesi", Endüstri Ilişskileri ve Insan Kaynakları Dergisi, cilt 8 , sayı 2, ss. 197-211. 